\title{
Management of Spinal Injury: Experience in Rajshahi Medical College Hospital
}

\author{
Md. Lutfor Rahman ${ }^{1}$, Md. Enamul Haque ${ }^{2}$, Md. S Zaman ${ }^{3}$, Md. Y Arafat ${ }^{4}$, Md. Intakhab Alam ${ }^{5}$
}

\begin{abstract}
Spinal injury is a critical neurosurgical emergency requiring prompt and highly skilled management. This study was carried out in the Neurosurgery unit of Rajshahi Medical College Hospital on 465 cases of spinal injury over 6 years. The age range of the patients was 4 to 72 years and most commonly involved age group was between 20 to 40 years. Male to female ratio was $5: 1$. Cervical spines were most commonly $(41 \%)$ affected by injury followed by thoracic $(13 \%)$, lumber $(36 \%)$, cervico-thoracic $(4 \%)$ and lumbo-thoracic spines $(6 \%)$. Common causes of spinal injury were fall trom height $(44,30 \%)$, RTA $(22.15 \%)$, heavy weight bearing $(13.11 \%)$ and assaulf with gun shot $(7.74 \%)$. Paraparesis was the most frequent $(55 \%)$ clinical presentation due to spinal injury followed by quadriparesis ( $45 \%$ ). Two third of the patients were managed conservatively and $9 \%$ required operative treatment. Mortality rate was $12 \%$ and $8 \%$ patient refused to take treatment.
\end{abstract}

TAJ 2002; 15(1): 25-27

\section{Introduction}

Historically, 5000 years ago surgical papyrus of Egypt described spinal cord injury as ailments not to be treated. ${ }^{i}$ Over the past few decades renewed interest in the treatment of spinal cord injuries resulted in improvement of emergency care, initial medical and surgical as well as rehabilitation of the crippled parients.? Treatment of dorso-lumber fractures is a controversial subject, trial of various methods, concluded that a combined anterior and posterior approach with shont segment fusion and stabilization is most appropriate ${ }^{2,3}$. The principal

of treatment of an unstable cervical spine injury protection and decompression of the cord realignment and stabilization ${ }^{3}$. The comer stone of contemporary spinal column injury management are $e^{4}$ (i) rapid detection (ii) immobilization (iii) early reduction of the spinal deformity and (iv) pharmacological therapy to facilitate neuronal function. The main focus of this study is to observe the neurosurgical role in the management of patients with spinal trauma.

\section{Patients and Methods}

This is a descriptive study done from January 1995 to December 2000. All the patients with spinal injury admitted during the said period are included in the study. Detailed history from each patient was taken; competent doctors performed meticulous clinical examination and neurological assessment. Relevant investigations were done as far as possible. Data were analyzed accordingly.

\footnotetext{
'Associate Professor, Department ol Neurosurgery, Aa shahi Medical College, Ra shahi-6000, Bangladesh

2 Assistant Registrar, Department of Neurosurgary. Rajshani Medical Colege, Rajshahi-5000, Bangladesh

Medical Officer. Department of Neurosurgery, Rajshahi Medical College Husplial. Rajshahi-6000, Bangiadest,

4 Medical Oticer, Department of Neurosurgery Rajshani Medical College Hospltal, Raishahi-6000, Bangladesh

${ }^{5}$ Assistant Professot. Department of Anaesthesiology, Rajshahi Medical Collegg. Rajshahi 6000, Bangladesh.
} 


\section{Result}

Out of 9736 patients admitted in the Neurosurgery unit of Rajshahi Medical College Hospital during the study period extending from January 1995 to December 2000 , four hundred sixty five $(5 \%)$ had sustained spinal injuries. Most $(56 \%)$ of the patients were young in the age range of 21 to 40 . Male to female ratio was $5: 1$. Cervical spines were most commonly $(41 \%)$ affected by injury followed by thoracic $(13 \%)$, lumber $(36 \%)$, cervico-thoracic
(4\%) and lumbo-thoracic spines $(6 \%)$. Common causes of spinal injury were fall from height $(44.30 \%)$, road traffic accidents $(22.15 \%)$, heavy weight bearing $(13.11 \%)$ and assault with gun shot (7.74\%). Paraparesis was the most frequent $(55 \%)$ clinical presentation due to spinal injury followed by quadriparesis $(45 \%)$. Two third of the patients were managed conservatively and $9 \%$ required operative treatment. Mortality rate was $12 \%$ and $8 \%$ patient refused to take treatment.

Table-I Causes of Spinal injury ( $\mathrm{n}=465$ )

\begin{tabular}{|l|c|c|}
\hline Causes of Spinal injury & No. of Patients & Percentage(\%) \\
\hline Fall from height (FFH) & 206 & 44.30 \\
\hline Road traffic accident (RTA) & 103 & 22.15 \\
\hline Heavy weight bearing & 69 & 14.84 \\
\hline Assault \& Gun shot injury & 36 & 7.74 \\
\hline Machinery injury & 24 & 5.16 \\
\hline Diving & 17 & 3.65 \\
\hline hanging & 10 & 2.15 \\
\hline
\end{tabular}

Table-II Sites of Spinal injury $(\mathrm{n}=465)$

\begin{tabular}{|l|c|c|}
\hline Sites of Spinal injury & No, of Patients & Percentage $(\%)$ \\
\hline Cervical & 193 & 41.50 \\
\hline Lumber & 167 & 35.91 \\
\hline Thoracic & 60 & 12.90 \\
\hline Thoraco-lumber & 27 & 5.80 \\
\hline Cervico-thoracic & 18 & 3.70 \\
\hline
\end{tabular}

Table-III Clinical features of Spinal injuries and Investigations ( $\mathrm{n}=465$ )

\begin{tabular}{|l|c|c|}
\hline Clinical features & No. of Patients & Percentage( $\%)$ \\
\hline Paraparesis/Paraplegia & 255 & 55 \\
\hline Quadriparesis/ Quadriplegia & 210 & 45 \\
\hline Neurogenic bladder & 112 & 24.1 \\
\hline
\end{tabular}

Table-IV: Treatment in Unstable Spinal injuries $(n=465)$

\begin{tabular}{|l|c|c|}
\hline \multicolumn{1}{|c|}{ Treatment } & No. of Patients & Percentage \\
\hline$\square$ Conservative & 333 & $71.61 \%$ \\
\hline$\square$ Operative & 42 & $09.03 \%$ \\
\hline$\square$ Refused to get treatment & 37 & $8 \%$ \\
\hline$\square$ Death & 53 & $12 \%$ \\
\hline
\end{tabular}

Table-V: Year wise occurrence of Spinal injury $(\mathrm{n}=465)$

\begin{tabular}{|l|c|c|}
\hline Year & Number of patients admitted in NSU & Spinal injury \\
\hline 1995 & 586 & 36 \\
\hline 1996 & 871 & 41 \\
\hline 1997 & 1980 & 85 \\
\hline 1998 & 1283 & 70 \\
\hline 1999 & 2583 & 97 \\
\hline 2000 & 2433 & 136 \\
\hline Total & 9736 & 465 \\
\hline
\end{tabular}




\section{Discussion}

Spinal Cord injuries can be related to the Mechanical insult, biochemical derangement and haemodynamic changes ${ }^{1}$. It is difficult to assess the degree of spinal cord injury pathology from clinical evaluation of neurologic deficits. Bohlman' showed, out of 300 Spinal injuries, 3 patients had normal cord microscopically. So it would seem appropriate to reduce fractures and dislocations immediately.

Treatment of neurologic deficit in spinal injured patients is done with immobilization, medical stabilization $\left(\mathrm{PO}_{2}, \mathrm{PCO}_{2}, \mathrm{CVP}, \mathrm{MAP}\right.$, monitoring etc), spinal alignments, operative decompression if there is proved cord compression and finally with spinal stabilization until osseous healing ${ }^{2}$,

In gun shot wound CSF leak out require operative dural closure and or removal of shell fragment of bullet compressing the neural structure Anterior decompression and stabilization is indicated with anterior compression, which ensures stabilization and enhances fusion rates, reduces the complication rates in complete spinal injuries ${ }^{3}$. Dorsal and lumber spinal injuries were surgically managed by late anterior decompression and stabilization done by bone graft in-patients who had incomplete neurological deficit ${ }^{4,5}$.

In spite of the absence of sublimation or dislocation, we must have MRI scan in every patient who has history of suspected spinal injuries. Tele medicine is recognized as a lifesaver in the more remote and poor regions of the world and satellite link provides access to better management now a days $s^{2}$.

\section{Conclusion}

Early surgical treatment is the choice for unstable injury of spinal cord for early ambulation and or to avoid complications of spinal injury and rehabilitation.

\section{Acknowledgment}

I am very much grateful to Directot; RMCH to allow me for publishing this artiele. I would also like to express my heartiest thanks to Dr. A.S.M. Shawkat Ali, Executive, Medical Services Department, Square Pharmaceuticals Lid. for extending his helping hand in making this manuscript.

\section{References}

1. Rathman, Simeone. The Spine. 2nd ed. 1982, 2:661.

2. Williams L, Wilkins. Clinical Neurosurgery 1998; 46 : 153-66.

3. Hadly MN, Argires PJ. The acute management of ventebral column fracture/dislocation injuries. Am Assoc Neurol Surg 1994; 11:249-62.

4. Rengachary GS, Wilkins RH. Principles of neurosurgery 1964; 20: 1-20.

5. Benzel EC, larson SJ. Functional recovery after decompressive spine operation for cervical fractures. Neurosurgery 1987; 20:742-56,

6. Wilmol CB, Hall KM. Evaluation of acute surgical intervention in traumatic paraplegia 1986; $24: 71$. 76.
All correspondence to:

Dr. Md. Luttor Pahman Associate Professor Depariment of Neurosurgery Rajshahi Medical College Raishahi-6000, Bangladesh. 